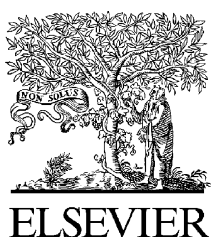

\title{
COPD management in the community: early detection and proactive care
}

The importance of Chronic Obstructive Pulmonary Disease (COPD) as a major yet neglected source of morbidity, mortality and health resource usage in primary care has been highlighted by a number of recent initiatives. A recent European Respiratory Society survey has reported that COPD affects $4-6 \%$ of adults in Europe [1], and it has been predicted that the rising disease burden of COPD will make it the third most common cause of death in the world by 2020 [2]. The clinical, human and economic costs of COPD are vast [3]. In spite of this, COPD has continued to suffer from a degree of neglect from many clinicians, researchers and healthcare planners [4], who have a tendency to view this disease as self-inflicted and untreatable. In contrast to this nihilistic attitude, the Global Obstructive Lung Disease (GOLD) project [5] of the World Health Organisation, has emphasised that COPD is a preventable and treatable condition and has defined global standards of care.

In the UK, the National Institute of Clinical Excellence (NICE) has laid down detailed guidance on the diagnosis and management of this condition in primary care [6] and has summarized the extensive body of literature of evidence-based effective interventions. Although at this stage the only interventions that have been proven to modify the course and prognosis of this inexorable disease are smoking cessation and long-term oxygen supplementation in respiratory failure, it is clear that there are many other interventions, both pharmacological and non-pharmacological, that can improve symptoms and quality of life, improve functional ability and reduce exacerbations, so helping to keep patients out of hospital and to lead a full and active life $[5,6]$.

The effort to improve the diagnosis and treatment of COPD in the community has received a boost from new contractual arrangements for general practitioners (GPs) in the United Kingdom; the new General Medical Services (nGMS) contract aims to encourage effective chronic disease management by providing quality-related payments to GPS reaching targets in a number of chronic iltnesses, including asthma and COPD [7]. The COPD quality indicator points are awarded on the basis of GPs maintaining an accurate disease register for COPD and meeting specified criteria for a proportion of patients on the register achieving targets in a number of areas: confirmation of the diagnosis by objective spirometric criteria in newly diagnosed and existing patients; recording of the FEV1 at least once every 27 months; recording of smoking status; provision of targeted smoking cessation advice; checking of inhaler technique; and use of annual influenza vaccination [7].

This initiative has had a galvanizing effect on COPD management in primary care in the UK, with a rapid expansion in spirometry provision in the community, an increase in COPD-related educational activity and a refreshing focus on respiratory outcomes. Many Primary Care Trusts (PCTs) have initiated programs of COPD care and there is a growing interest in the training and accreditation of General Practitioners with a Special Interest (GPwSI) in respiratory medicine [8-11] in order to co-ordinate community respiratory initiatives centering on COPD. 
Is all well then with the GMS contract and COPD care in the UK community? Whilst there is much to be applauded in the nGMS COPD section, on some issues there are concerns that the advice could be improved. Quality markers are by necessity limited to specific measurable parameters and over-concentration on these aspects of the disease may occur at the expense of a more holistic, thorough, clinical approach.

Our immediate concern is, however, the potential confusion amongst UK GPs resulting from a difference in diagnostic criteria for COPD in the nGMS regulations as compared to the NICE Guidelines for COPD [6]. The nGMS regulations [7] advocate a diagnosis of COPD if 'the patient has an FEV1 of less than $70 \%$ of predicted normal and has an FEV1/FVC ratio of less than $70 \%$ and there is less than $15 \%$ response to a reversibility test' [8]. In contrast, evidence-based guidelines for the diagnosis of COPD, including NICE [5] and GOLD [6] define COPD by an FEV1 of $80 \%$ predicted or less together with an FEV1/FVC ratio of less than $70 \%$ and lack of reversibility. The rationale for the lower nGMS threshold (70\% predicted FEV1) for diagnosing COPD is that a significant number of patients with a higher FEV1 may have minimal symptoms. The use of $70 \%$ in nGMS enables clinicians to concentrate on symptomatic COPD'.

There are a number of significant problems with this policy;

- The justification for re-defining a disease with national and internationally agreed diagnostic criteria is questionable.

- The correlation between symptoms, quality of life impairment and lung function is poor in COPD, with some patients having considerable symptoms despite relatively normal lung function even at an early stage in the disease. The recent demonstration in the European Community Respiratory Health Survey of a significant prevalence of early COPD even in younger smokers [12] points to the need for early detection and active management at all stages of the disease; in this survey even patients with mild early disease had impaired health and increased use of healthcare resources.

- The nGMS approach effectively denies those patients with early COPD access to targeted smoking cessation, structured proactive care and vaccination recall lists. Smoking cessation is the single most important intervention in the management of COPD [13].

COPD is a major challenge to all interested in primary care respiratory medicine; it is heartening to find a growing interest in the illness and a growing will to offer best quality care in the community. However, as COPD is an illness that has no cure, we must continue to strive for early detection and active management at all stages of the disease. The cycle of inactivity, social isolation, depression and de-conditioning so well described in COPD should be prevented from developing rather than us waiting for disease progression to occur before intervening.

The COPD diagnostic criteria in the UK nGMS contract will, in our opinion, delay diagnosis of treatable COPD, and will deny patients early access to proactive care; this includes vaccination, pharmacological and non-pharmacological interventions, and early active encouragement of healthy lifestyle measures including smoking cessation, improved diet and increased exercise.

\section{References}

[1] European Respiratory Society. European Lung White Book. Lausanne, Switzerland: European Respiratory Society, 2003;1-182.

[2] Lopez AD, Murray CC. The globah burden of disease, 1990-2020. Nat Med 1998;4:1241-3.

[3] Pauwels RA, "Rabe KF. Burden and clinical features of chronic obstructive pulmonary disease (COPD). Lancet 2004;364:613-20.

[4] Barnes P, Kleinert S. COPD-A neglected disease. Lancet 2004;364:564-5.

[5] Global Initiative for Chronic Obstructive Lung Disease (GOLD). Global strategy for the diagnosis, management, and prevention of chronic obstructive pulmonary disease. NHLBI/WHO Workshop Report, 2003: www.goldcopd.com/ workshop/index.html (accessed Aug, 2004).

[6] National Institute for Clinical Excellence. Chronic obstructive pulmonary disease: management of adults with chronic obstructive pulmonary disease in primary and secondary care. 2004. Available at: http://www.nice.org.uk/ page. aspx?o=106422.

[7] GMS Contract 2003 -'Investing in General practice' (Blue Book). Quality and Outcomes Framework: COPD. http://www.bma.org.uk/ap.nsf/Content2/ QualityOutcomesclinicalcopd (accessed October 2004).

[8] Williams S, Ryan D, Price D, et al. General practitioners with a special clinical interest: a model for improving respiratory disease management. British Journal of General Practice 2002;52(483):838-43.

[9] Gruffydd-Jones K. The framework for general practitioners with a special interest in respiratory medicine. Prim Care Resp J 2003;12(2):35 (accessed October 2004) http://www.gpiag.org/journ/vol12_2/035_ 035gruffyddjones.pdf.

[10] Ryan D. Why have GPwSls in respiratory medicine? Prim Care Resp J 2003;12(2):36 (accessed October 2004) http://www.gpiag.org/journ/vol12_2/036_036ryan.pdf.

[11] Campbell M, Cotton P, Everden P, et al. General practitioners with a special interest in respiratory medicine. Prim Care Resp J 2003;12(2):38-41 (accessed October 2004) http://www.gpiag.org/journ/vol12_2/038_ 041gruffyddjones.pdf.

[12] de Marco R, Accordini S, Cerveri I, et al. for the European Community Respiratory Health Survey (ECRHS) Study Group. 
An international survey of chronic obstructive pulmonary disease in young adults according to GOLD stages. Thorax 2004; 59:120-5.

[13] Fletcher C, Peto R. The natural history of chronic airflow obstruction. BMJ 1977;1:1645-8.

Mike Thomas

Department of General Practice, University of Aberdeen, Gloucestershire Research and

Devlopment Support Unit
Minchinhampton, Gloucestershire, UK Corresponding author E-mail address: mikethomas@doctors.org.uk

Mark L. Levy

Division of Community Health Sciences: GP Section, University of Edinburgh, UK E-mail address: marklevy@animalswild.com

19 October 2004

\section{Available online at http://www.thepcrj.com}

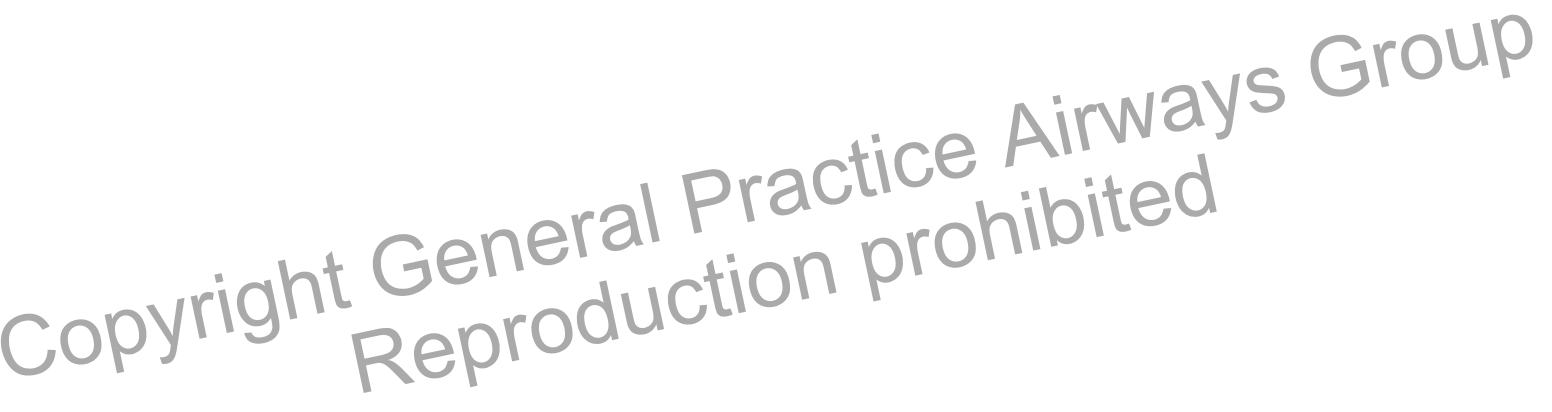

